Revista de Derecho

\title{
Post Comisión de la Verdad: expresiones artísticas y emergencia de sentidos
}

Post truth commission: artistics expressions and emergency of senses

María L. Cristina Solís Ch.

Facultad Latinoamericana de Ciencias Sociales, FLACSO

cristasoy@yahoo.com

DOI: https://doi.org/10.32719/26312484.2019.31.3

Fecha de recepción: 2 de abril de 2018

Fecha de aprobación: 26 de febrero de 2019 


\section{RESUMEN}

En 2007 se creó en Ecuador una Comisión de la Verdad (CVE) con el objetivo de investigar hechos violatorios a los derechos humanos ocurridos durante el período 1984-2008, así como de formular políticas de reparación, judicialización y reformas institucionales. Durante su investigación, la CVE incorporó como fuentes de información tanto testimonios de víctimas y/o sus familiares como documentación desclasificada proveniente de archivos de instituciones militares y policiales, además de algunas denuncias documentadas de la Comisión Ecuménica de Derechos Humanos (CEDHU). El proceso desatado por la CVE dio paso a procesos de formulación de políticas dirigidas a la judicialización y reparación, pero también impulsó a la emergencia de otras acciones y expresiones diversas -que sobrepasaron los límites de lo jurídico e institucional-, favoreciendo el aparecimiento de un escenario compartido entre memorias convergentes y disidentes de un pasado de violencia política. Estas últimas ofrecen visiones alternativas a la oficial.

Palabras Clave: Comisión de la Verdad, justicia transicional, trabajos de la memoria, sentidos del pasado, expresiones artísticas.

\section{ABSTRACT}

In 2007 a Truth Commission (CVE initials in spanish) was created in Ecuador with the objective of investigating facts that violated human rights that occurred during the period 1984-2008, as well as formulating reparation, judicialization and institutional reforms policies. During its investigation, the CVE incorporated as sources of information both testimonies of victims and / or their relatives as declassified documentation from archives of military and police institutions, as well as some documented complaints from the Comisión Ecuménica de Derechos Humanos (CEDHU). The process unleashed by the CVE gave way to processes for formulating policies aimed at judicialization and reparation, but it also gave way to the emergence of other actions and diverse expressions -which went beyond legal and institutional boundaries- favoring the appearance of a shared scenario between convergent and dissident memories of a past of political violence, the latter offer alternative views to the official one.

KeYwords: Truth Commission, transitional justice, works of memory, meanings of the past, artistic expressions. 


\section{LA COMISIÓN DE LA VERDAD EN ECUADOR Y SU BÚSQUEDA DE VERDAD}

$\mathrm{E}$ n 2007, a pocos meses de iniciado el gobierno del economista Rafael Correa, mediante decreto presidencial fue creada una Comisión de la Verdad para Ecuador (CVE), ${ }^{1}$ a la que se le encargó la investigación sobre hechos violatorios a los derechos humanos ocurridos durante el período correspondiente a los años 1984-2008, aunque con énfasis en el gobierno del ingeniero León Febres Cordero. ${ }^{2}$ En el artículo 2 del decreto se establece "realizar una investigación profunda e independiente de los hechos ocurridos entre 1984 y 1988, y otros casos especiales". También se le encargó la formulación de políticas de reparación material e inmaterial, de judicialización y reformas institucionales.

El decreto de formación de la CVE en 200 viabiliza una iniciativa pública enmarcada dentro de las medidas de la justicia transicional, entendida esta como "los procesos penales, de depuración y de reparación que tienen lugar después de la transición de un régimen político a otro", ${ }^{3}$ que se ha desarrollado durante las últimas cuatro décadas como un campo que tiene características propias, pues surgió como respuesta a un determinado tipo de violaciones de derechos humanos, aquellas asociadas al ejercicio abusivo, represivo y violento del poder por parte de las dictaduras latinoamericanas de los años setenta y ochenta del siglo XX. Pretende combatir la impunidad de esos delitos en los países donde han ocurrido, a través del establecimiento de medidas para esclarecer la verdad sobre violencia estatal en el pasado reciente; reformar las instituciones que las hicieron posible; judicializar los casos; y promulgar políticas de reparación material y simbólica a favor de las víctimas.

1. Las Comisiones de la Verdad son una de las medidas que hacen parte de la justicia transicional, esta última tiene que ver con "procesos y mecanismos asociados con los intentos de una sociedad por resolver los problemas derivados de un pasado de abusos a gran escala, a fin de que los responsables rindan cuentas de sus actos, servir a la justicia y lograr la reconciliación. Tales mecanismos pueden ser judiciales o extrajudiciales y tener distintos niveles de participación internacional (o carecer por completo de ella) así como abarcar el enjuiciamiento de personas, el resarcimiento, la búsqueda de la verdad, la reforma institucional, la investigación de antecedentes, la remoción del cargo o combinaciones de todos ellos". Kofi Annan, citado en Pablo Greiff, "Algunas reflexiones acerca del desarrollo de la Justicia", Anuario de derechos Humanos 7 (2011): 17-9, 〈www.anuariocdh.uchile.cl〉.

2. Líder del Partido Social Cristiano, antes de lanzarse como candidato presidencial fue diputado (19791983). Dos años después de terminar la presidencia, en 1992, fue electo alcalde de Guayaquil, cargo que lo ocupó hasta 2000. En 2002 fue elegido diputado nacional para el período 2002-2006, siendo reelegido para el mismo cargo en 2006, pero se retiró por motivos de salud a principios de 2007. Murió en diciembre de 2008.

3. Jon Elster, Rendición de cuentas: la justicia transicional en perspectiva histórica (Buenos Aires: Katz, 2006). 
A partir de esas características es importante preguntarse: ¿por qué se promueve una CVE en 2007? Una posible respuesta podría ser que se presenta como un dispositivo simbólico fundacional, pues cuando las comisiones de la verdad aportan con elementos para producir un nuevo relato sobre el pasado violento de una país, también entregan elementos para producir un relato de distanciamiento, de discontinuidad con ese pasado. "El presente se presenta purificado, descontaminado y desconectado del viejo orden autoritario". "Precisamente esto sería, según Krupa, lo que el presidente Correa buscaría con la creación de la "Comisión de la Verdad: ni silencio, ni impunidad", marcar una discontinuidad con el pasado relacionado con aquello que él se dio en calificar como "la larga y triste noche neoliberal", con el ánimo de desacreditar y deslegitimar a los partidos políticos que desde 1978 hasta 2007 habían dominado el escenario político del país. Esto explicaría el énfasis en establecer diferencias con el período 1984-1988, que corresponde a la presidencia del ingeniero León Febres Cordero, quien suele ser identificado no solo como un gobernante autoritario, sino como el iniciador del neoliberalismo en Ecuador. ${ }^{5}$

La CEV en su investigación para esclarecer la verdad incorporó como fuentes de información más de 600 testimonios de víctimas y/o sus familiares, así como documentación desclasificada proveniente de archivos del Consejo de Seguridad Nacional (COSENA), Ministerio de Defensa y Policía Nacional, además de algunas denuncias documentadas por la Comisión Ecuménica de Derechos Humanos (CEDHU), todo lo que le permitió configurar $118^{6}$ casos de violaciones a los derechos humanos que

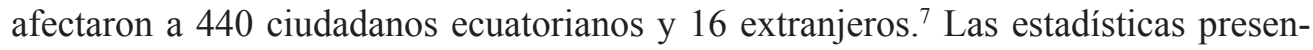
tadas en el informe final Sin Verdad no hay justicia ${ }^{8}$ señalan que el 68\% de los casos sucedieron entre 1984 y 1988, mientras que el 32\% entre 1989 y 2008. En relación a

4. Christopher Krupa, "Neoliberal Reckoning Ecuador's Truth Commission and the Mythopoetics of Political Violence", en Neoliberalism Interrupted. Social Change and Contested Governance in Contemporary Latin America, ed. por Mark Goodale y Nancy Postero (California: Stanford University Press Stanford, 2013), 171.

5. César Montúfar, La reconstrucción neoliberal. Febres Cordero o la estatización del neoliberalismo en el Ecuador 1984-1988 (Quito: Abya-Yala, 2000).

6. En el informe final se describen 118 casos, pero luego de la entrega del informe, se prorrogó una vez más el mandato de la CVE, esto fue de agosto a diciembre de 2010 y "se le facultó para recibir y documentar nuevos casos de violaciones de derechos humanos ocurridos entre 1984 y 2008 . En estos cinco meses, la CV recibió 22 nuevos casos, algunos del período de León Febres Cordero y otros de años más recientes” (Valencia 2011, 240).

7. Tanto la CVE creada mediante Decreto Ejecutivo como la Dirección de la Comisión de la Verdad y Derechos Humanos creada en la Fiscalía reconocen el subregistro de casos.

8. El informe comprende: resumen ejecutivo; tomo 1: violaciones a los derechos humanos; tomo 2: crímenes de lesa humanidad; tomo 3: relatos de casos período 1984-1988; tomo 4: relatos de casos período 19892008; tomo 5: conclusiones y recomendaciones. 
los presuntos responsables se identificaron a 459 personas, de las cuales "el 49, 6\% corresponde a oficiales activos y pasivos de la Policía Nacional, el 28, 3\% a miembros activos y pasivos de las tres ramas de las Fuerza Armadas, el 10\% a autoridades de Gobierno, el 5,4\% a funcionarios judiciales y el 5,9\% a autoridades o agentes de Estados extranjeros". ${ }^{9}$ Como lugares de cometimiento de los abusos se señalan centros policiales y militares (fuerza terrestre, naval y área) así como dependencias públicas y algunos sitios clandestinos específicamente destinados a ese objetivo. Las violaciones que se identificaron como más frecuentes fueron: la tortura, la privación arbitraria de la libertad, la violencia sexual, las ejecuciones extrajudiciales y las desapariciones forzadas.

Esa búsqueda de la verdad, recuperando memoria testimonial y documental, evidenció que efectivamente se dieron hechos violatorios a los derechos humanos cometidos por el Estado, además de que estos fueron deliberadamente ocultados, distorsionados o falseados ante la ciudadanía y opinión pública a través de una narrativa oficial que pretendió un carácter de verdad. La verdad que se conoce sobre las acciones de represión estatal llevadas adelante en el período investigado fue producida en el sentido que sostiene Hannah Arendt: "en la época moderna la verdad no está dada ni revelada sino que es producida por la mente humana". ${ }^{10}$ Esto conduce a establecer una diferencia entre verdad de razón y verdad de hecho, que al trasladarse al campo de lo político plantea un conflicto entre verdad política y verdad factual. "Nadie al parecer jamás creyera que la mentira organizada, tal como la conocemos hoy en día, podría ser un arma adecuada contra la verdad". ${ }^{11}$

La verdad producida en Ecuador requirió de algunos recursos para inducir al olvido, al ocultamiento o a la distorsión de información sobre los hechos que interesan. Uno de los principales recursos -compartido por todas las dictaduras y gobiernos autoritarios de la región- fue la construcción de la imagen del enemigo interno que ponía en riesgo a la estabilidad de la nación, ese enemigo interno era el otro, cuya identidad había que delinear, a la vez que satanizar como terroristas, subversivos, insurgentes, narcotraficantes, delincuentes o narcoguerrilleros. La construcción de este tipo de otredad negativa ${ }^{12}$ por parte del Estado tuvo como efecto inmediato justificar el uso indiscriminado de la represión política y violencia estatal. Intencionalmente

9. Alejandro Valencia, "Memorias compartidas: las comisiones de la verdad de Paraguay y Ecuador", en Contribución de las políticas de verdad, justicia y reparación a las democracias en América Latina, ed. por Instituto Interamericano de Derechos Humanos (San José: IIDH, 2011), 231.

10. Hannah Arendt, Verdad y política (Barcelona: Ediciones Península, 1968), 5.

11. Ibíd., 5 .

12. Daniel Feierstein, El genocidio como práctica social. Entre el nazismo y la experiencia Argentina (Buenos Aires: Fondo de Cultura Económica, 2007). 
la referencia al enemigo interno, al otro peligroso, se hacía de forma amplia y ambigua, incluyendo a líderes, militantes, simpatizantes de partidos de izquierda tradicionales, de organizaciones sindicales, gremiales, campesinas, populares, estudiantiles, religiosas, ${ }^{13}$ a defensores de los derechos humanos, a periodistas, así como a miembros de las organizaciones políticas-militares Alfaro Vive Carajo (AVC) ${ }^{14}$ y Montoneras Patria libre (MPL) ${ }^{15}$ Amplitud y ambigüedad que facilitó al discurso oficial equiparar la otredad política con la otredad criminal, cuya máxima expresión sería el terrorismo, creando la ficción de la presencia de un enemigo interno de proporciones alarmantes.

crear la ilusión de la existencia de una organización aparentemente poderosa y sofisticada, cuando en realidad no lo era. La ilusión implicó, como se ha afirmado, crear la narrativa de la infamia incluso creando evidencias cuando no las había [...] Las acciones de Alfaro Vive fueron amplificadas por el gobierno gracias a su política de comunicación, dicha amplificación tuvo en la práctica un papel justificador de la respuesta represiva contra amplios sectores de la población y a la postre de las violaciones de derechos humanos generalizadas que conllevaron. ${ }^{16}$

Otros recursos para inducir al olvido fueron: convertir en tema tabú las acciones llevadas adelante por parte de la Policía, de las Fuerzas Armadas del Ecuador, de las instancias de justicia, de los expertos extranjeros en el asesoramiento para combatir al enemigo interno; así como la negación sistemática tanto de las violaciones a los derechos humanos cometidas en el gobierno de Febres Cordero como de las cometidas con posterioridad. La banalizaciòn de las acciones del Estado contra los opositores, desvalorizándolos, reduciendo su existencia a una nuda vida ${ }^{17}$ una vida sin cualidad,

13. No por su participación política en el ámbito público, sino por su papel en la defensa de derechos humanos... la Iglesia, que muchas veces apoyaba a quienes tenían que huir o refugiarse, fue muy solidaria en ese sentido (HEM, defensora de los derechos humanos y comisionada, entrevista 28 de mayo de 2015).

14. AVC salió a la luz pública en 1983 con el robo de las espadas del expresidente Eloy Alfaro, se dieron a conocer como una agrupación político-militar de línea alfarista con acciones de "propaganda" como pintas de paredes, tomas de radio, medios impresos y emisiones clandestinas de proclamas, y más tarde con acciones de "propaganda armada" y de "recuperación económica", estas últimas financiaban la organización. Para 1986, como resultado de las políticas represivas del gobierno de Febres Cordero, la cúpula de la agrupación fue aniquilada selectivamente vía ejecuciones extrajudiciales, mientras que los AVC sobrevivientes fueron apresados, quedando desarticulada la organización.

15. En enero de 1986 un grupo de AVC decidió separarse por diferencias estratégico-políticas con el comando central y formar una nueva agrupación. A partir de entonces inician acciones para darse a conocer públicamente, de recuperación económica y reclutamiento en varias zonas del país. Al finalizar el gobierno de Febres Cordero, la cúpula y muchos de sus militantes estaban en prisión.

16. Comisión de la Verdad Ecuador, Informe final: Sin verdad no hay justicia. Resumen ejecutivo (Quito: Comisión de la Verdad, 2010), 248-9.

17. Giorgio Agamben, Homo sacer. El poder soberano y la nuda vida (Valencia: Pretextos, 2006). 
una vida desnuda, a un cuerpo sin alma generando un sentido común ciudadano ${ }^{18}$ que llevó a identificar al enemigo interno y los riesgos que este representaba para el país con categorías equivalentes de delincuente, asaltabancos, subversivo, sedicioso, criminal, terrorista, guerrillero o narcotraficante al utilizarlas indistintamente en los discursos oficiales y en los de los medios de comunicación.

Siguiendo a Hannah Arendt, se puede decir que se provocó un choque entre la verdad factual y la verdad política, lo que se configura como un problema político de primer orden, pues "surge la sospecha de que puede estar en la naturaleza del campo político negar o tergiversar cualquier clase de verdad, como si los hombres fueran incapaces de llegar a un acuerdo con la pertinencia inconmovible, evidente y firme de esa verdad". ${ }^{19}$

\section{EL ESCLARECIMIENTO DE LA VERDAD DESDE LA MIRADA DE LA CVE Y NUEVOS SENTIDOS SOBRE EL PASADO DE VIOLENCIA ESTATAL}

La CVE, como una medida de justicia transicional, reconoce en el informe Sin verdad no hay justicia sus alcances y límites: "[...] es una entidad temporal e independiente, establecida por las autoridades, sin atributos judiciales, que se enfoca en violaciones graves de los derechos humanos o del derecho internacional humanitario; que investiga patrones de abusos y tiende a mirar el pasado con una lente centrada en las víctimas". ${ }^{20}$

Volver la mirada al pasado desde la lente de las víctimas le permitió a la CVE evidenciar que la memoria, entendida como "las formas en que la gente construye un sentido del pasado", ${ }^{21}$ estaba activa en los recuerdos de las víctimas, de sus familiares y testigos de violencia estatal, a pesar de que había sido silenciada, marginada y sometida a políticas de olvido por distintos gobiernos y por distintos mecanismos, "memorias silenciadas en el mundo público pero conservadas y transmitidas en el ámbito privado (familiar o de sociabilidad clandestina), guardadas en la intimidad personal, 'olvidadas en un olvido evasivo' -porque pueden ser memorias prohibidas,

18. Andrés, Guerrero, "El proceso de identificación: sentido común ciudadano, ventriloquia y transescritura", en Etnicidades, comp. por Andrés Guerrero (Quito: FLACSO, 2000).

19. Arendt, Verdad y politica, 10.

20. Comisión de la Verdad Ecuador, Informe final: Sin verdad no hay justicia, 14.

21. Alon Confino, "Collective Memory and Cultural History: Problems of Method", American Historical Review 102, n. ${ }^{\circ} 5$ (1997): 1387, 〈http://www.jstor.org/stable/2171069〉. 
indecibles o vergonzantes". ${ }^{22}$ Además que esa memoria podía ser contrastada con la huella material que de esos hechos quedó inscrita en documentos oficiales guardados en archivos institucionales, interpelando la narrativa oficial, que a pesar de haber sido puesta en duda por algunos sectores y actores, se configuró como hegemónica hasta la entrega del informe en junio de 2010.

El aporte de la CVE al esclarecimiento de la verdad es de enorme significación, pues -aunque haya incurrido en ciertas omisiones y olvidos que tienen que ver, entre otras cosas, con el corte temporal definido para la investigación y con el subregistro de los casos, logró traer el pasado de violencia política de vuelta, cuestionarlo, cambiar su sentido desde el presente y producir una nueva verdad sobre nuestra historia reciente como la entienden La Capra y Lvovichv ${ }^{23}$ acercando la historia a la memoria para acceder al pasado y a sus memorias traumáticas. Así, la CVE crea las condiciones para que las personas antes silenciadas, marginadas e invisibilizadas sean reconocidas como víctimas y aparezcan en el espacio público hablando ante la comisión de investigación, en documentales, en charlas, en entrevistas, en juicios, contando su versión de los hechos, interpelando al pasado de violencia política y a la producción de narrativas que los convirtieron en un otro negativo, peligroso y, por lo tanto, excluible material y simbólicamente de la sociedad. Su memoria y su voz favorecieron sus posibilidades de recuperar espacios de acción política, evitando con ello que el borramiento social de su existencia sea irreversible.

La recuperación de la memoria testimonial y documental que la investigación de la CVE realizó, brinda información que se ha ganado el derecho de ser considerada e incorporada en la historia reciente del país, al tiempo que se ha convertido en medio para interponer reclamos de justicia, dando pie a lo que se conoce como deber de memoria,$^{24}$ que busca trasladar el trabajo de memoria al campo de lo ético-político.

22. Elizabeth Jelin, Los trabajos de la memoria (Madrid: Siglo XXI Editores, 2002), 43.

23. Aparece como un campo de conocimiento en construcción, pueden mencionarse como características propias, "la cercanía temporal o coetaneidad entre pasado y presente, la supervivencia de quienes protagonizaron esa historia, la existencia de una memoria social viva sobre ese pasado o la contemporaneidad entre el historiador y su objeto de investigación" (Daniel Lvovich, "Historia reciente de pasados traumáticos. De los fascismos y colaboracionismos europeos a la historia de la última dictadura Argentina". En Historia reciente: perspectivas y desafíos para un campo en construcción (Buenos Aires: Paidós, 2007), 13-4. Según La Capra: "se ocupa de procesos sociales traumáticos (genocidios, terrorismo de Estado, guerras), dirigiendo nuevamente la mirada al acontecimiento, pero ahora lo hace a través del prisma de la memoria de los sobrevivientes de experiencias violentas, traumáticas, dolorosas implementadas por estados totalitarios, autoritarios o dictaduras, cuyas voces y relatos habían sido censurados". Dominik La Capra, Historia en tránsito: experiencia, identidad, teoría crítica (Buenos Aires: Fondo de Cultura Económica, 2006), 17.

24. Walter Benjamin, Tesis sobre la historia y otros fragmentos, edición y traducción de Bolívar Echeverría (México D. F.: Universidad Autónoma de México, 2008). 
El testigo y su testimonio permiten volver la mirada al pasado desde el presente, y a la vez permiten la presencia del pasado en el presente gracias a que sus recuerdos se catapultan hacia la acción y al reclamo de justicia y reparación.

Sin embargo, la judicialización, esperanza largamente sostenida por las víctimas y/o sus familiares, ha transitado a pasos lentos por laberintos procedimentales. Desde la entrega del informe final en junio de 2010 hasta que finalizó el gobierno de Correa en mayo de 2017, se llevaron a proceso judicial once casos de los ciento dieciocho identificados en ese informe: ocho por graves violaciones a los derechos humanos y tres por crímenes de lesa humanidad (ninguno de los tres llegó a etapa de juicio). Esto de cierta forma ha ido minando la esperanza de las víctimas, cuyos casos no avanzan a la etapa de juicio y sentencia, o la de aquellos cuyos casos han quedado empantanados en la etapa de indagación previa, favoreciendo la impunidad de los autores intelectuales y materiales (civiles y militares) de los delitos de tortura, desapariciones forzadas, ejecuciones extrajudiciales, violaciones sexuales y privaciones ilegales de libertad cometidos entre 1984 y 2008.

Por otro lado, en cuanto a las acciones estatales para dar seguimiento y concreción a las recomendaciones del informe Sin verdad no hay justicia se pueden mencionar algunos hitos importantes: la Ley para la Reparación de las Víctimas y la Judicialización de Graves Violaciones de Derechos Humanos y Delitos de Lesa humanidad Ocurridos en el Ecuador entre el 4 de Octubre de 1983 y 31 de Diciembre de 2008, aprobada en la Asamblea Nacional en diciembre de 2013; la aprobación del nuevo Código Integral Penal (COIP) en 2014, en el que se incorporaron reformas referentes a delitos contra la humanidad y a graves violaciones a los derechos humanos; además, se tipificaron infracciones como la omisión de denuncia de tortura, la desaparición forzada y la violencia sexual en conflicto armado. A nivel institucional se creó al interior de la Fiscalía General del Estado la Dirección de la Comisión de la Verdad y Derechos Humanos como instancia especializada para judicializar los casos, mientras que al interior de la Defensoría del Pueblo se creó la Dirección Nacional de Reparación a Víctimas; además, se encargó al Ministerio de Justicia la elaboración y firma de convenios indemnizatorios para los casos que tuvieran lugar.

\section{SENTIDOS Y EXPRESIONES EN DISENSO POST CoMisión de la Verdad Ecuador}

Mientras los procesos de judicialización y reparación material e inmaterial adquirían un ritmo propio pautado por las lógicas y dinámicas político-administrativas, otras recepciones al informe de la CVE se fueron multiplicando y gestando en espacios que sobrepasaron los límites de lo jurídico, de lo normativo e institucional, favo- 
reciendo la configuración de un escenario que puso en escena memorias convergentes y disidentes del pasado de violencia política en el país, haciendo visibles las pugnas por los sentidos del pasado, pues si bien "el pasado no se puede cambiar, su sentido sí". ${ }^{25}$ Lo que da cuenta de la conflictividad que podría llegar a generarse por los usos del pasado en el presente.

El trabajo investigativo de la CVE y su informe se convirtieron en catapultador de trabajos de la memoria, como diría Jelin, ${ }^{26}$ es decir, de acciones y producciones dirigidas a recordar, a denunciar, reformular o a interpelar desde el presente la versión oficial sobre la represión y violencia estatal ocurrida en el país, o, por el contario, para mantener vigente la versión oficial. Una explosión de voces y sentires aparecieron contando sus experiencias personales o contando las experiencias de los otros o las percepciones de un posible nosotros como país. Durante la década que va desde la expedición del decreto de formación de la CVE en 2007 hasta el fin del gobierno de la Revolución Ciudadana en 2017, diversas producciones y publicaciones provenientes de iniciativas tanto privadas como públicas surgieron para dar cuenta de las discontinuidades y continuidades entre pasado y presente, permitiendo entender al pasado, como sostiene Ricoeur, ${ }^{27}$ "como aquello que ha sido, y no como lo que ha dejado de ser", para evitar convertirlo en algo clausurado, cerrado. Tanto la memoria colectiva como la individual tienen el privilegio de transitar del presente al pasado, y viceversa, tejiendo hilos de continuidad o discontinuidad en la trama del tiempo, hilvanando, deshilvanando o zurciendo las roturas de la historia. Eso es posible cuando las condiciones del presente (políticas, sociales y culturales) son receptivas a nuevas lecturas del pasado. Los eventos pasados solo se pueden recuperar en un entorno colectivo "si encajan en el marco de los intereses contemporáneos". ${ }^{28}$

Otros entramados de la historia oficial sobre la violencia política en Ecuador en el período 1984 y 2008, han sido posibles, como hemos visto en el campo de la jurisprudencia y de la administración pública, pero se han dado también en la literatura, en el cine documental, en la pintura mural, en la música, entre otras producciones que pueden ser vistas como formas de "romper con la conformidad de lecturas domesticadas por los lugares comunes del rito institucional, de las tradiciones hegemónicas, de los

25. Paul Ricoeur, La lectura del tiempo pasado: memoria y olvido. El cuidado de lo inolvidable (Madrid: Universidad Autónoma de Madrid, 1999).

26. Elizabeth Jelin, Los trabajos de la memoria (Madrid: Siglo XXI Editores, 2002).

27. Paul Ricoeur, La memoria, la historia y el olvido (Madrid: Trotta, 2003).

28. Wulf Kansteiner, "Finding Meaning in Memory: A methodological Critique of Collective Memory", History and Theory, 41, n. $^{\circ} 2$ (2002): 185. 
saberes oficiales, de sus jerarquías disciplinarias, del mercado cultural" ${ }^{29}$ Existen, por supuesto, anteriores a ese período, pero surgieron bajo otras circunstancias.

Un repaso breve sobre esas producciones da cuenta de las otras formas de hacer memoria que se han hecho públicas, por ejemplo, entre los libros se puede mencionar: Calla y respira, de Hernando Calvo Ospina (2012); ¿Dónde está la sangre del pueblo?, una recopilación de escritos de Arturo Jarrín (2012); Memoria de las espadas, de Antonio Rodríguez (2014); Memorias de un subversivo, de Franklin Escobar (2015). Mientras que en la producción de cine documental encontramos: Archivos de la Comisión de la Verdad (2010); Con mi corazón en Yambo, de María Fernanda Restrepo, estrenado en 2011; La memoria de los peces, del Ministerio de Cultura; La muerte de Roldós, de Manolo Sarmiento y Lisandra Rivera, estrenado en 2013; y El documental de Alfaro Vive Carajo, de Mauricio Samaniego, estrenado en 2015.

En pintura mural el "Grito de la memoria", encargado por la Fiscalía General del Estado al artista Pavel Egüez, develado en diciembre de 2014. La producción musical cuenta con los discos El infiernillo: 1984-1988. Memoria y testimonio de nuestro Pueblo, iniciativa de la Subsecretaría de Memoria Social del Ministerio de Cultura; y Yuri Moncada el combatiente, del grupo Tierra Libre.

Los autores de los libros ponen como eje el hecho de haber experimentado directamente y/o haber sido testigos de la represión y violencia del Estado; insertan en la trama su historia personal como parte de la historia reciente del país, en un movimiento narrativo que teje su memoria personal, su experiencia vital con la memoria colectiva de un período y un espacio en particular. Lo mismo sucede con los documentales de María Fernanda Restrepo, Mauricio Samaniego y el del Ministerio de Cultura, producciones que remiten a las reflexiones de Maurice Halbwachs, quien sostiene que existe una "memoria individual, portadora de marcos sociales, es decir, estructurada por la sociedad, se encuentra una memoria en la sociedad a la manera de una memoria individual y, finalmente se encuentra un individuo que sería el lugar de coexistencia e interacción de memorias colectivas: un individuo que sería la sociedad". ${ }^{30}$

El autor enfatiza en la naturaleza social de aquello que se recuerda o se olvida, es decir, que lo que se almacena, deshecha o reprime en la memoria individual, así como las representaciones o las interpretaciones que se hacen del pasado, están influenciadas por el entorno social, espacial y temporal en que cada persona está inserta. "La idea de una memoria individual, totalmente separada de la memoria social, es una

29. Nelly Richard, La insubordinación de los signos (Santiago: Editorial Cuarto Propio, 1994), 17.

30. Maurice Halbwachs, Los marcos sociales de la memoria (Barcelona: Antrophos, 2004), 387. 
abstracción carente de sentido". ${ }^{31}$ Como vemos, los marcos sociales (espaciales y temporales) de la memoria pueden hacer y deshacer la memoria colectiva.

Mientras que en los documentales de Manolo Sarmiento y Lisandra Rivera, y el de la Comisión de la Verdad, son los otros los que cuentan, investigan, hurgan en la memoria de los otros, al parecer buscando un nosotros, una identidad colectiva que logre emanciparse de la tiranía del olvido obligado, como sostiene Ricoeur: "Lo más difícil no es 'contar de otra manera o dejarse 'contar por otros', sino contar de otra manera los acontecimientos fundadores de nuestra propia identidad colectiva, principalmente nacional; y dejar que los cuenten otros [...]". ${ }^{32}$

En esta línea estaría también el mural Grito de la memoria ${ }^{33}$ del artista Pavel Egüez, y da un paso más allá en su interpretación de memoria colectiva al representar tanto la violación de los derechos humanos ocurridas en la región durante las décadas de los setenta y ochenta, como en Ecuador, en particular en el período 1984-1988, pero no exclusivamente, así como a los personajes responsables del cometimiento de esos delitos y a los que se enfrentaron a la represión.

Este mural es de alguna manera un testimonio, en donde los ciudadanos de Quito, las personas que visiten esta ciudad, sepan que hay un espacio de memoria donde recordar esos hechos tiene que servirnos para que la sociedad no vuelva a cometer ese olvido, y el Estado ecuatoriano no vuelva a cometer esos crímenes de lesa humanidad y esas violaciones a los derechos humanos (Egüez, entrevista). ${ }^{34}$

El gran formato de la obra se apodera del espacio público, se hace visible para todas las personas que transiten por sus alrededores, expresando la posición política del autor, no solo en su contenido sino en su opción por el muralismo, que acerca el arte al ciudadano de a pie.

Por el lado discográfico está el Infiernillo, resultado de una propuesta del Ministerio de Cultura para juntar a intérpretes y cantautores de izquierda de los ochenta con intérpretes y cantautores jóvenes en una producción que combina temas clásicos e inéditos relacionados con la violación de los derechos humanos ocurrida en el país

31. Halbwachs, citado en Wulf Kansteiner, "Finding Meaning in Memory: A methodological Critique of Collective Memory", History and Theory, 41, n. 2 (2002): 185.

32. Paul Ricoeur, La lectura del tiempo pasado: Memoria y olvido (Madrid: Universidad Autónoma de Madrid, 1999), 7.

33. Encargado por la Fiscalía General del Estado, inaugurado el 10 de diciembre de 2014, con motivo del día de los derechos humanos, ubicado simbólicamente en la pared exterior del edificio de Fiscalía, cuyo anterior ocupante fue la Embajada de Estados Unidos de América.

34. Pavel Egüez, entrevistado por Ves televisión, 16 de diciembre de 2014, «https://www.youtube.com/ watch?v=fXqtjDYgS-M> (consulta el 16 de enero de 2016). 
en 1984-1988, con el propósito de rememorar hechos de violencia estatal del pasado, resignificándolos y trasmitiéndolos a grupos que no los experimentaron. Además, el disco Yuri Moncada el combatiente, que hace parte del homenaje que el grupo Tierra Libre hizo a Yuri Moncada, exmiembro de Alfaro Vive Carajo y del Batallón América, muerto en combate en Colombia, quien a su vez fue también exintegrante del grupo musical. El primer tiraje de este disco fue financiado por la Secretaría de Pueblos en $2012,{ }^{35}$ el segundo con fondos familiares.

Examinando toda esta producción se pueden observar otras formas en que la memoria(s) se expresan evidenciando recepciones y sentidos diversos sobre las memorias que la justicia transicional en Ecuador, a través de la Comisión de la Verdad, documentó con pruebas testimoniales y materiales. Estas expresiones confrontan las políticas y los discursos oficiales que justificaron el cometimiento de graves violaciones a los derechos humanos y crímenes de lesa humanidad en el país en el pasado reciente. Al emerger en el disenso con la versión oficial le devuelven a la memoria su politicidad, en términos de Rancière, ${ }^{36}$ quien considera que la política se instaura justamente en el momento en que el disenso frente al orden social impuesto se expresa, cuando una parte de la sociedad que no es reconocida como tal, actúa, habla, demanda su visibilidad, y de alguna manera esa demanda supone un reacomodo o una ruptura de ese orden establecido:

Solo hay política cuando esas maquinarias [el ejercicio de la majestad, el vicariato de la divinidad, la gestión de intereses] son interrumpidas por el efecto de un supuesto que les es completamente ajeno y sin el cual, sin embargo, en última instancia ninguna de ellas podría funcionar: el supuesto de la igualdad de cualquiera con cualquiera, esto es, en definitiva, la eficacia paradójica de la contingencia de todo orden. ${ }^{37}$

Es a propósito de las irrupciones de esas obras, que al mismo tiempo recuerdan e interpretan el pasado, que se abre el relato a lecturas contrarias al orden establecido y que se puede experimentar cierta igualdad, pues aquello que estaba oculto se visibiliza; aquellos que no tenían lugar, se toman un espacio; aquellos que no eran escuchados, se hacen escuchar. Estas irrupciones artísticas tienen, por otro lado, el potencial de favorecer también el reacomodo de subjetividades, percepciones, representaciones, interpretaciones sobre los hechos de violencia política ocurridos en Ecuador, gracias a que son nuevas formas de visibilidad y legibilidad de esos acontecimientos. Aunque es difícil conocer los efectos que ejercen sobre los lectores, sobre los espectadores o

35. Siendo en ese momento Rosa Mireya Cárdenas (exmilitante de Alfaro Vive Carajo), la secretaria de Pueblos, Movimientos Sociales y Participación Ciudadana.

36. Jacques Rancière, El desacuerdo: política y filosofía (Buenos Aires: Ediciones Nueva Visión, 1996).

37. Ibíd., 32 . 
el público al que llegan, no se puede negar que algún efecto tendrán si acordamos con Rancière que estos no son pasivos, pues "mirar es también una acción que confirma o que transforma esta distribución de las posiciones. El espectador también actúa [...]. Observa, selecciona, compara, interpreta. Liga aquello que ve a muchas otras cosas que ha visto". ${ }^{38}$ Nuevas asociaciones y disociaciones surgirán de aquello que observa, lee, escucha, precisamente "ese es el poder del espectador emancipado". ${ }^{39}$

\section{SENTIDOS Y EXPRESIONES CONVERGENTES A LA JUSTIFICACIÓN DE LA VIOLENCIA ESTATAL INVESTIGADA POR LA CVE}

Por otro lado, aparecieron producciones alineadas al discurso oficial del febrescorderato y de las instituciones policiales y militares involucradas en planificar y ejecutar las políticas represivas que conllevaron al cometimiento de los delitos de graves violaciones de derechos humanos y crímenes de lesa humanidad, pretendiendo deslegitimar la emergencia de nuevas voces, de nuevas versiones, de nuevas formas de sentir, de ver, de decir.

Cuando en 2007 se conoció públicamente la conformación de la CVE, el expresidente Febres Cordero expresó su rechazo a esta instancia, que desde su punto de vista "Es inconstitucional, espuria, antiética e inmoral... Es una expresión auténtica de lo que es Correa: un hombre caprichoso, totalitario [...] la Comisión fue integrada 'con dedicatoria', para perseguirme, con personajes vinculados a Alfaro Vive Carajo". ${ }^{40}$ Sus reacciones frente al resultado del trabajo de la CVE y frente al informe final no se pudieron conocer debido a que murió el 15 de diciembre de 2008, pero sí fueron públicas las de sus familiares, colaboradores y coidearios, quienes además de rechazar el trabajo de la Comisión, propusieron la colocación de un monumento a Febres Cordero en un lugar simbólico de la ciudad de Guayaquil. La propuesta generó controversias entre las autoridades locales y las del gobierno central, este último a través de argumentos normativos trató de impedir que se instale el monumento; además, intentó hacer uso de una de las recomendaciones de la CVE que se refiere a "instar al Gobierno central y a los gobiernos autónomos descentralizados para que desmantelen monumentos públicos y eliminen nombres de lugares públicos, incluyendo centros educativos, de personas responsables de violaciones de derechos humanos". ${ }^{41}$

\footnotetext{
38. Jacques Rancière, El espectador emancipado (Buenos Aires: Ediciones Manantial, 2010), 19.

39. Ibíd.

40. León Febres Cordero, "Harb: Febres Cordero no se siente aludido", El Universo, 9 de septiembre de 2008, 〈https://www.eluniverso.com/2008/09/09/0001/8/8CDB656CAC23432093A59E24880CD436.html〉.

41. Comisión de la Verdad Ecuador, Informe Final: Sin verdad no hay justicia, 406.
} 
Mientras transcurría la disputa, se encargó la realización de la obra al escultor español Víctor Ocho. Finalmente, los esfuerzos del Gobierno fracasaron, y en agosto de 2014 el busto de Febres Cordero fue colocado en el Malecón 2000, eje histórico, comercial y turístico de la ciudad de Guayaquil. En la ceremonia de desvelamiento el alcalde de la ciudad, Jaime Nebot, dijo sobre el expresidente: "Errores tuvo como todos aquellos que tenemos la decisión de resolver y hacer cosas, pero sus aciertos fueron muy superiores. Como presidente de la República luchó con valentía y entereza para que este país no se convierta en empresa del terrorismo sangriento $[\ldots] .^{42}$

Disputa a nivel simbólico muy importante, pues gira alrededor no solo de la imagen de Febres Cordero, sino de los lugares de memoria, ${ }^{43}$ ya que en actos como estos la memoria se inscribe en un lugar y se materializa. La colocación del busto de Febres Cordero articula un lugar físico a la memoria, a ese lugar se le dota de contenidos simbólicos, de significados culturales y políticos que se deben rememorar y conmemorar, con la intencionalidad de que pasen a formar parte de la memoria colectiva de los habitantes de la ciudad. Lo mismo ocurre con las publicaciones que también pueden ser consideradas lugares de memoria. El grupo de coidearios, partidarios y familiares ha publicado León, Guayaquil vive por ti (2009) y León a viva voz (2015), textos que comparten la intencionalidad de inscribir en la memoria colectiva de los ciudadanos de Guayaquil recuerdos seleccionados con el fin de resaltar ciertas características del perfil político del expresidente e invisibilizar otras. Poniendo con ello en evidencia que las disputas por la memoria implican luchas por quien se apodera del recuerdo, por "quien decide lo que se debe recordar o lo que se debe olvidar y de cómo hacerlo". ${ }^{44}$

La Policía Nacional se pronunció sobre el informe de la CEV, al que considera mentiroso, en 2009, y adelantándose a los resultados de las investigaciones, miembros del servicio pasivo crearon una comisión paralela denominada Comisión Jurídico Institucional de la Policía Nacional, con el objetivo de que sea la vocera de la verdad institucional. En octubre del mismo año publicó la primera edición del libro Terrorismo y subversión. La verdad que no se ha dicho, en el cual se describen las acciones delictivas de propaganda armada y de recuperación económica que ejecutaron en el país los grupos subversivos Alfaro Vive Carajo, Montoneras Patria Libre y el movimiento M-19 de Colombia, esto en base a informes y documentos de los Servicios de

42. Jaime Nebot, "Se inauguró busto de León Febres Cordero en Guayaquil", El Universo, 27 de agosto de 2014, 〈https://www.eluniverso.com/noticias/2014/08/27/nota/3574356/se-inauguro-busto-leon-febrescordero-guayaquil».

43. Pierre Nora, "La aventura de Les lieux de mémoire", Revista Ayer, n. 32 (1998): 17-34.

44. Peter Burke, "History and Social Memory", en The Collective Memory Reader, ed. por Jeffrey Olick, (New York: Oxford University Press, 2011). 
Investigación Criminal SIC, Unidad de Investigaciones Especiales UIES, Inteligencia Policial y publicaciones en la prensa escrita del Ecuador y Colombia. El interés está centrado en posicionar su versión, su verdad sobre los hechos investigados por la CVE, a la vez que justificar el accionar de la institución:

TERRORISMO Y SUBVERSIÓN, descifra los hechos de un ayer que laceró al Ecuador y no logró integralmente sus propósitos, gracias a la actuación de una legión de profesionales del orden y la seguridad, que utilizando las armas idóneas y legales otorgadas por el Estado, supo combatirlos y marginarlos, salvando a la sociedad de la violencia inclemente, el terrorismo destructor y la subversión política irrazonada. ${ }^{45}$

La Comisión autora del libro considera que frente a la mentira que se fragua en las investigaciones de la $\mathrm{CEV}$, que da crédito a los testimonios de quienes pusieron en vilo al país, deben recordar "al lector, amante de LA VERDAD, lo que en efecto sucedió dos décadas atrás, cuando la paz, la seguridad y la tranquilidad de toda la población ecuatoriana, se vio no solo amenazada, sino ultrajada, por grupos subversivos que sembraron el terror y tiñeron con sangre de inocentes, el sagrado territorio de nuestra patria". ${ }^{46}$ El texto señala los grupos que pusieron en riesgo a la sociedad ecuatoriana: la delincuencia común, la delincuencia organizada y la delincuencia subversiva, incluso incluye una lista con nombres y apellidos. De esa lista llama poderosamente la atención que se menciona a la Comisión Ecuménica de Derechos Humanos y a la Hna. Elsie Monge, comisionada de la CVE e histórica directora de la CEDHU, como cómplice y protectora de delincuentes y asesinos. Luego, en 2015, la Asociación de Generales de la Policía Nacional con el objetivo de dar a conocer su postura frente a los casos llevados a juicio por graves violaciones a los derechos humanos y crímenes de lesa humanidad que involucran a miembros de la institución y de las Fuerzas Armadas publicaron el texto "Reflexiones jurídicas sobre delitos de lesa humanidad", en el que se argumenta sobre la ilegalidad en la conformación de la CVE y sobre los principios penales que deben acogerse para la defensa de los acusados, basándose en experiencias internacionales de defensa a victimarios en los juicios por este tipo de delitos.

Por otro lado, el mismo año 2015, tres exagentes del equipo de seguridad del expresidente Febres Cordero publicaron el libro Sobrevivientes de un magnicidio, Taura 28 años después, 1987-2015. Sus autores, Patricio Robado, Segundo Papel y Carlos Solís, califican como heroica la acción de los agentes que murieron durante el taurazo y que

45. Comisión de Defensa Jurídico-institucional de la Policía, Terrorismo y subversión. La verdad que no se ha dicho, 2. ${ }^{a}$ ed. (Quito: Comisión de Defensa Jurídico-Institucional de la Policía Nacional, 2010), 7.

46. Ibíd., 16. 
significó salvar la vida del expresidente Febres Cordero del intento de magnicidio perpetrado por los comandos de Taura; además, acusan a la CVE de parcializada: "Y como dice Robado, quedó evidenciada la actuación parcializada de la Comisión de la Verdad que en su informe, verdadera apología del delito, pone a los alzados en armas (insurrectos) como víctimas, mientras ignoran a las verdaderas víctimas". ${ }^{47}$

\section{CONCLUSIONES}

La conformación de una Comisión de la Verdad en Ecuador desató una serie de acciones y políticas dirigidas al esclarecimiento de la verdad, justicia y reparación a víctimas de la violencia estatal ocurrida entre los años 1984-2008, pero también desató una serie de acciones y expresiones que podrían considerarse como trabajos de la memoria. Todo esto ha contribuido a mostrar que la historia sobre la violencia estatal se presentó fragmentada, interrumpida y muchas veces distorsionada por las voces oficiales, pero que sin embargo ha podido ser replanteada en una(s) nueva(s) narrativa(s) gracias a la irrupción de voces y visiones alternativas sobre ese pasado. La información entregada por la CVE permite zurcir o hilvanar fragmentos desechados de la versión oficial, que recuperan memorias individuales de la violencia, las mismas que a su vez recuperan los marcos espaciales, temporales y sociales que las relacionan y así poder replantear el lugar de esos acontecimientos en la memoria colectiva.

El trabajo de la memoria realizado por la CVE y post Comisión por otros actores permite, por otro lado, comprender que distintas temporalidades pueden y deben encontrarse en el presente dando cuenta de las formas en que el pasado genera diversos sentidos. Documentales, libros, expresiones artísticas, entre otras producciones han evitado que en Ecuador el pasado se vuelva fijo, intocable, inmutable, removiendo las diferentes capas de tierra, de polvo, de sedimento que se formaron debido al olvido, el ocultamiento, la negación, la banalización del mal, el tabú, el silencio con que se cubrieron las violaciones a los derechos humanos y los crímenes de lesa humanidad en Ecuador, en el período mencionado, y se pretenden seguir justificando.

Indudablemente estas producciones están disputando desde el presente el sentido del pasado, evidenciando contradicciones, omisiones, tensiones entre recuerdo y olvido que en toda psiquis y en toda sociedad se presentan en relación a la interpretación o representación del pasado. Las pugnas por el pasado, sobre todo por los sentidos del pasado de violencia política experimentados en el país, se vienen dando en el

47. Xavier Neira, "Del caso Taurazo", El Universo, 13 de enero de 2016, 〈http://www.eluniverso.com/opinion/2016/01/13/nota/5342182/caso-taurazo>. 
presente, como vemos, pero es importante mencionar que la posibilidad de influenciar en las percepciones sociales sobre esos acontecimientos a través de esta serie de producciones convergentes o disidentes, depende más que de su producción y de su autor, de la recepción que haga el espectador, el lector, el público en general, del efecto que produzcan en su subjetividad, del tipo de elementos que aportan a la decodificación de verdades oficiales, que dominan las percepciones sobre determinados hechos, así como a la decodificación de marcos de vigilancia, de policía, de ordenamiento social "naturalizados" al punto de consolidarse como hegemónicos.

\section{BIBLIOGRAFÍA}

Agamben, Giorgio. Homo sacer. El poder soberano y la nuda vida. Valencia: Pretextos, 2006. Arendt, Hannah. Verdad y política. Barcelona: Ediciones Península, 1968.

Benjamin, Walter. Tesis sobre la historia y otros fragmentos. Edición y traducción Bolívar Echeverría. México D. F.: Universidad Autónoma de México, 2008.

Burke, Peter. "History and Social Memory". En The Collective Memory Reader, editado por Jeffrey Olick. New York: Oxford University Press, 2011.

Comisión de Defensa Jurídico-institucional de la Policía. Terrorismo y subversión. La verdad que no se ha dicho. Quito: Comisión de Defensa Jurídico-institucional de la Policía, 2010.

Comisión de la Verdad Ecuador. Informe final: Sin verdad no hay justicia. Resumen ejecutivo. Quito: Comisión de la Verdad, 2010.

-. Informe final: Sin verdad no hay justicia. Tomos 1-5. Quito: Comisión de la Verdad, 2010.

Confino, Allon. "Collective Memory and Cultural History: Problems of Method". American Historical Review, 102, n. ${ }^{0} 5$ (1997): 1386-403. «ttp://www.jstor.org/stable/2171069〉.

Elster, Jon. Rendición de cuentas: la justicia transicional en perspectiva histórica. Buenos Aires: Katz, 2006.

Feierstein, Daniel. El genocidio como práctica social. Entre el nazismo y la experiencia argentina. Buenos Aires: Fondo de Cultura Económica, 2007.

Guerrero, Andrés. "El proceso de identificación: sentido común ciudadano, ventriloquia y transescritura", en Etnicidades, compilado por Andrés Guerrero, 9-60. Quito: FLACSO, 2000.

Halbwachs, Maurice. Los marcos sociales de la memoria. Barcelona: Antrophos, 2004.

Jelin, Elizabeth. Los trabajos de la memoria. Madrid: Siglo XXI Editores, 2002.

Kansteiner, Wulf. "Finding Meaning in Memory: A methodological Critique of Collective Memory". History and Theory, 41, n. $^{\circ} 2$ (2002): 179-97. 〈http://www.jstor.org/stable/3590762〉.

Krupa, Christopher. "Neoliberal Reckoning Ecuador's Truth Commission and the Mythopoetics of Political Violence". En Neoliberalism Interrupted. Social Change and Contested 
Governance in Contemporary Latin America, editado por Mark Goodale and Nancy Postero, 169-194. California: Stanford University Press Stanford, 2013.

La Capra, Dominik. Historia en tránsito: experiencia, identidad, teoría crítica. Buenos Aires: Fondo de Cultura Económica, 2006.

Lvovich, Daniel. "Historia reciente de pasados traumáticos. De los fascismos y colaboracionismos europeos a la historia de la última dictadura argentina”. En Historia reciente: perspectivas y desafios para un campo en construcción, 97-124. Buenos Aires: Paidós, 2007.

Montúfar, César. La reconstrucción neoliberal. Febres Cordero o la estatización del neoliberalismo en el Ecuador 1984-1988. Quito: Abya-Yala, 2000.

Nora, Pierre. "La aventura de Les lieux de mémoire. Memoria e Historia". Revista Ayer, n. 32 (1998): 17-34.

Rancière, Jacques. El desacuerdo: política y filosofía. Buenos Aires: Nueva Visión, 2012.

—. El espectador emancipado. Buenos Aires: Ediciones Manantial, 2010.

Richard, Nelly. La insubordinación de los signos. Santiago: Editorial Cuarto Propio, 1994.

Ricoeur, Paul. La lectura del tiempo pasado: memoria y olvido. El cuidado de lo inolvidable. Madrid: Universidad Autónoma de Madrid, 1999.

—. La memoria, la historia y el olvido. Madrid: Trotta, 2003.

Valencia, Alejandro. "Memorias compartidas: las Comisiones de la Verdad de Paraguay y Ecuador". En Contribución de las políticas de verdad, justicia y reparación a las democracias en América Latina, editado por Instituto Interamericano de Derechos Humanos 215-54. San José: IIDH, 2011. 